\title{
Prevalence of skin infections, infestations, and papular urticaria among adolescents in secondary schools in Calabar, Nigeria
}

\author{
Eshan B. Henshaw ${ }^{1}$ and Olayinka A. Olasode ${ }^{2}$ \\ Ghana Med J 2019; 53(4): 287-293 doi: http://dx.doi.org/10.4314/gmj.v53i4.6 \\ ${ }^{1}$ Department of Internal Medicine, University of Calabar, Eta Agbor Road, Calabar, Cross River State, Nigeria \\ ${ }^{2}$ Department of Dermatology, Obafemi Awolowo University, Ile-Ife, Osun State, Nigeria
}

Corresponding author: Dr. Eshan B. Henshaw Conflict of interest: None declared
E-mail: eshenshaw@unical.edu.ng

\section{SUMMARY}

Background: Acne is an inflammatory disorder of the pilosebaceous gland, and the most common dermatosis in adolescents globally. Infectious dermatoses are common in the tropics, but due to the paucity of epidemiologic surveys, not much is known about the prevalence and common types found in different sub-populations including adolescents. It is however presumed that the prevalence will be high and the pattern diverse. We therefore conducted a school-based survey to ascertain the prevalence and pattern of infectious dermatoses, infestations, and papular urticaria (insect bite reactions) in teenage adolescents in Calabar, Nigeria.

Methods: A cross sectional observational survey of adolescents aged 13-19 years attending randomly selected secondary schools in Calabar, Nigeria. It involved the use of questionnaires and subsequent whole body examination.

Results: A total of 1447 senior secondary school students were examined. Infectious dermatoses, infestations, and papular urticaria (IDIP) were observed in 505 (34.9\%) persons, among whom were 269 (53.3\%) males, and 236 (46.7\%) females $\left(X^{2}=34.87, p=<0.001\right)$. Fungal dermatoses constituted more than $90 \%$ of the diseases, the bulk of which was contributed by pityriasis versicolor [430 (79.6\%)]. The six most common dermatoses in descending order of frequencies were Pityriasis versicolor, tinea, papular urticaria, candidiasis, furuncles, and viral warts.

Conclusion: A high prevalence of cutaneous infections exists among teenage adolescents in Calabar, Nigeria. Males have a higher predisposition to fungal dermatoses. Control of the predominant cause of cutaneous infections - pityriasis versicolor, will significantly affect the prevalence of infectious dermatoses, and invariably, the burden of skin disorders in adolescents in Calabar, Nigeria.

Keywords: Dermatoses, Infections, Adolescents, Nigeria, Prevalence Funding: Self sponsored

\section{INTRODUCTION}

Infectious diseases, also known as communicable diseases, are abundant in the tropics. The warm and humid tropical climate favours the growth and replication of infective organisms. This has allowed the terms 'infectious' and 'tropical' to be used interchangeably when referring to diseases caused by infective agents. According to the World Health Organization, adolescence is a developmental stage made up of persons aged $10-19$ years. Teenagers (13 - 19 years) form the bulk of persons in this group. The period of adolescence heralds the transition from childhood to adulthood and comes with a higher level of independence. Compared to the childhood period, adolescence is marked by increase in peer-related outdoor and sporting activities, leading to more personperson and person-soil contact.
This higher degree of environmental exposure involves less adult supervision, but at this stage, the adolescent has greater autonomy with respect to personal hygiene and grooming. Hygiene issues of a child is more or less a reflection of parental care, the adolescent on the other hand assumes responsibility for the status of his/her hygiene. Adolescence is also a time when relationships are developed, and lasting friendships forged; hence conditions which adversely affect physical appearance or psyche can lead to social isolation and a negative impact on the quality of life. ${ }^{1}$ Skin diseases are known to negatively impact the quality of life of sufferers, particularly adolescents. ${ }^{2}$ Certain infectious dermatoses which cause overt discoloration of the skin - such as pityriasis versicolor (PV) - are common among adolescents in the tropics. ${ }^{3,4}$ 
This is an innocuous treatable dermatosis which adults may not consider serious enough to merit consultation with a physician. However, due to its visibility (particularly in dark skin), it may constitute a major physical impairment in adolescents, especially as it is erroneously associated with poor hygiene by the lay public. ${ }^{5}$ Adolescents who live in the tropics, particularly those in low income economies tend to present with a more varied range of dermatoses, and a higher prevalence of cutaneous infections than their contemporaries in other climes, even those in high income tropical regions. ${ }^{3,6-8}$

This study was conducted in Calabar, a city located in what is referred to as the South-South geopolitical zone of Nigeria. There are two distinct climatic seasons in Nigeria: the rainy season between March and October; and the dry season between November and February. In recent times however, the rains often persist into the month of December, particularly in the southern part of the country. The rainfall in Calabar is usually heavy, with high humidity during the rains. The weather becomes drier and hotter in the dry season. The study was done in November 2008, just at the beginning of the dry season, at which time the mean temperature and humidity was $31.6^{\circ} \mathrm{C}$ and $87 \%$ respectively, with an average rainfall of $102.5 \mathrm{~mm}$. (Data obtained from the Nigerian meteorological agency at the Margaret Ekpo International airport, Calabar).

Orthodox medical services became available to the indigenes of Calabar in 1897, but specialist dermatologic services were not offered for over a century after. This left the population with undetermined and unmet skin health needs until the advent of a dermatologist in 2006. It thus became imperative that the dermatologic needs of the population be determined. This epidemiologic survey seeks to address this situation by determining the prevalence of infective dermatoses among a subset of the population of Calabar. Infective dermatoses are largely treatable, thus it is important to ascertain the predominant types in adolescents, to enable the requisite interventional measures, and reduce the burden of skin diseases in adolescents in this environment.

\section{METHODS}

This was a cross sectional type of observational study wherein senior secondary students aged $13-19$ years attending co-educational public and private day schools were recruited via a multistage stratified random sampling method. The process involved determination of the number of schools in Calabar, and an initial stratification into public and private schools, followed by the random selection of eight schools - four from each stratum. The minimum sample size was determined using the formula for large population in a cross-sectional survey developed by Cochran, and the number of students recruited was proportionally allocated to the selected schools. There was further stratification into forms and the number of students to be recruited from each form was determined by proportional allocation, followed by random selection of subjects irrespective of gender. Thus each student had an equal probability of being chosen.

Pre-tested semi-structured questionnaires which sought to obtain sociodemographic information were administered to the randomly recruited subjects by a dermatologist and six assistants (medical personnel). Some of the questions required input from parents/guardians, thus the students were allowed to take home the questionnaires and return them before the date set for physical examination of the skin. Whole body examination (genitalia excluded) of all those who completed and returned their questionnaires was conducted in private rooms with good natural light.

The assistants, who had been pre-trained by the dermatologist to methodically examine the skin, were to identify persons with skin disorders; all such persons were sent to the dermatologist who made the diagnoses. This was mainly clinical. The study was reviewed and approved by the ethics committee of the University of Calabar Teaching Hospital (UCTH/CS\&T/Vol.8/115), and permission granted by the Commissioner at the State Ministry of Education to use the public schools. Permission was also sought from the management of private schools and verbal and written consent obtained from both students and their parents/guardians respectively.

Data was analysed using Statistical Package for the Social Sciences (SPSS) version 15 and involved the use of descriptive statistics such as frequencies and percentages, and cross tabulation procedures to analyse categorical variables for which the chi square test was used to test the significance of associations. The test was adjudged significant when the $p$ value was $\leq 0.05$.

\section{RESULTS}

One thousand four hundred and forty seven (1447) senior secondary (SS) students were examined - 590, 588, and 264 from SS 1 (Grade 10), SS 2 (Grade 11), and SS 3 (Grade 12) respectively. Of these number, 505 (34.9\%) had one or more infectious dermatoses, infestation, or papular urticaria. More males than females, and younger compared to older teenagers presented with infectious dermatoses (ID). Table 1 shows the details of some sociodemographic variables and compares persons with and without infective dermatoses. 
Table 1 Distribution of infective dermatoses based on sociodemographic characteristics

\begin{tabular}{|c|c|c|c|}
\hline \multirow[t]{2}{*}{ Variable } & \multicolumn{2}{|c|}{$\begin{array}{l}\text { Presence of cutaneous in- } \\
\text { fections } n(\%)\end{array}$} & \multirow[t]{2}{*}{$\mathrm{X}^{2}$} \\
\hline & $\begin{array}{l}\text { No } \\
942(65.1)\end{array}$ & $\begin{array}{l}\text { Yes } \\
505(34.9)\end{array}$ & \\
\hline $\begin{array}{l}\text { Gender } \\
\text { Male } \\
\text { Female }\end{array}$ & $\begin{array}{l}350(56.5) \\
592(71.5)\end{array}$ & $\begin{array}{l}269(43.5) \\
236(28.5)\end{array}$ & 34.87 \\
\hline $\begin{array}{l}\text { Age } \\
\text { Early teens (13-16 years) } \\
\text { Late teens (17-19 years) }\end{array}$ & $\begin{array}{l}518(64.0) \\
424(66.5)\end{array}$ & $\begin{array}{l}291(36.0) \\
214(33.5)\end{array}$ & 0.93 \\
\hline $\begin{array}{c}\text { School type } \\
\text { Private } \\
\text { Public }\end{array}$ & $\begin{array}{l}275(61.0) \\
667(67.0)\end{array}$ & $\begin{array}{l}176(39.0) \\
329(33.0)\end{array}$ & 4.91 \\
\hline $\begin{array}{l}\text { Class* } \\
\text { SS } 1 \text { (Grade 10) } \\
\text { SS } 2 \text { (Grade 11) } \\
\text { SS } 3 \text { (Grade 12) }\end{array}$ & $\begin{array}{l}361(61.2) \\
376(63.9) \\
202(76.5)\end{array}$ & $\begin{array}{l}229(38.8) \\
212(36.1) \\
62(23.5)\end{array}$ & 19.47 \\
\hline
\end{tabular}

Ten cutaneous infections/infestations/insect bites induced disorders were identified, with fungal dermatoses forming a significant bulk of all disorders. Scabies was the only parasitic infestation observed and had the lowest prevalence $(0.7 \%)$. Furuncles, warts, and papular urticaria were the most common bacterial, viral, and insect bite-induced skin disorders, with equal point prevalence of $1.7 \%$ for the first and second dermatoses, and 3.3\% for papular urticaria - as presented in Table 2.

Table 2 Prevalence and pattern of specific infective skin disorders

\begin{tabular}{|c|ll|}
\hline Infective dermatoses & $\begin{array}{l}\text { Frequency } \\
\text { n (\%) [540] }\end{array}$ \\
\hline Fungal & $496(91.9)$ \\
Candidiasis & $14(2.6)$ \\
Dermatophytosis & 52 & $(9.6)$ \\
Pityriasis versicolor & $430(79.6)$ \\
\hline Bacterial & 12 & $(2.2)$ \\
Furuncles & 9 & $(1.7)$ \\
Hansens & 1 & $(0.2)$ \\
Trichomycosis axillaries & 2 & $(0.4)$ \\
\hline Viral & 10 & $(1.9)$ \\
Warts & 9 & $(1.7)$ \\
Herpes simplex infection & 1 & $(0.2)$ \\
\hline Parasitic & 4 & $(0.7)$ \\
Scabies & 4 & $(0.7)$ \\
\hline Insect bite reaction & 18 & $(3.3)$ \\
Papular urticaria & 18 & $(3.3)$ \\
\hline
\end{tabular}

Comparison of the six most common diseases based on gender, showed tinea infection, pityriasis versicolor and viral warts to be more predominant among males, but only the first two were of statistical significance. On the other hand, cutaneous candidiasis, furuncles, and papular urticaria were more commonly seen in females, but none was statistically significant. The detailed values of the foregoing can be seen in Table 3 .
Table 3 Gender comparison of the six most common infective dermatoses

\begin{tabular}{|c|c|c|c|c|}
\hline \multirow{2}{*}{$\begin{array}{l}\text { p-Skin Disease } \\
\text { value }\end{array}$} & \multicolumn{2}{|l|}{ Gender } & \multirow[t]{2}{*}{$\mathbf{X}^{2}$ or $\mathbf{L} L^{*}$} & \multirow{2}{*}{$\begin{array}{l}\text { p- } \\
\text { value }\end{array}$} \\
\hline & $\begin{array}{l}\text { Male } \\
{[269]} \\
\text { n(\%) }\end{array}$ & $\begin{array}{l}\text { Female } \\
{[236] \mathrm{n}(\%)}\end{array}$ & & \\
\hline Tinea Infections & $41(6.6)$ & $11(1.3)$ & 28.67 & $<0.001$ \\
\hline $\begin{array}{l}\text { Cutaneous candidia- } \\
\text { sis }\end{array}$ & $3(0.5)$ & $11(1.3)$ & $2.85 *$ & 0.091 \\
\hline Pityriasis versicolor & $223(36.0)$ & $207(25.0)$ & 20.62 & $<0.001$ \\
\hline Papular urticaria & $6(1.0)$ & $12(1.4)$ & 0.68 & 0.409 \\
\hline 0. F\&ârunculosis & $2(0.3)$ & $7(0.8)$ & $1.69 *$ & 0.194 \\
\hline Viral warts & $5(0.8)$ & $4(0.5)$ & $0.60 *$ & 0.44 \\
\hline
\end{tabular}

One of the challenges of reporting surveys of skin diseases in adolescents (except for specific conditions like acne vulgaris) is the relatively few studies that focus exclusively on adolescents, particularly teenagers. Most surveys merge children with adolescents or adolescents with adults, limiting realistic comparisons with studies like ours which has an adolescent homogeneity. This has to be borne in mind in the course of our discussion, as age is an important factor affecting the distribution of skin diseases. A typical example is seen in a study among students aged 6 to 21 in Hong Kong, the commonest dermatoses in the survey was acne vulgaris, which had an adolescent to child ratio of 10:1. The converse was seen in atopic dermatitis, which predominated among the children, with a child to adolescent ratio of 4.7:1.9

This study confirms the preponderance of ID among adolescents living in the tropics. A similar prevalence of $33.9 \%$ was reported by Ogunbiyi et al. ${ }^{4}$ in a survey of students aged $10-20$ years old in Southwest Nigeria. In Chanigarh, India, a surprisingly lower prevalence of $16.4 \%$ was reported by Dogra and Kumar10 in a study of children aged $6-14$ years (infections are presumed to be commoner in children and young adolescents). While India shares similar socioeconomic characteristics as Nigeria, the climate in Chandigarh is described as warm and temperate. ${ }^{11}$ This, in addition to the design of the survey might account for the lower prevalence. As envisaged, a low prevalence of $2.5 \%$ was recorded in a survey of adolescents in Hong Kong. ${ }^{9}$

The climate in Hong Kong is similar to that in Nigeria, however, the cosmopolitan high income city is well developed, with available social infrastructure and almost ideal environmental conditions, it also boasts of a robust healthcare system. There were significantly more infectious dermatoses in males than females, consistent with the observations of Morakinyo et $\mathrm{al}^{12}$ among younger children. 


\section{Original Article}

In contrast, Souissi et $\mathrm{al}^{13}$ found a slightly higher frequency of infectious skin diseases among females in Tunis, although this was a clinic-based study which involved all ages.

Superficial fungal infection (SFI) was the most common group of infectious dermatoses. Similar findings were reported in Ibadan4 and Hong Kong. ${ }^{9}$ This mirrors the general trend seen in many hospital based surveys of skin diseases from the African continent, such as those involving an admixture of adults and children in Tunisia, Nigeria, and Egypt. ${ }^{13-15}$ Surprisingly, they were also the most common cutaneous infections in developed countries like Japan and Turkey. ${ }^{16,17}$ However, a different picture emerged among the subset of adolescents in hospital based surveys: while SFI remained the predominant condition in Egypt, ${ }^{18}$ viral warts were more common in Japan, Turkey, Tunisia and Switzerland. . $^{16,17,19,20}$

It should be noted that SFI was the predominant finding in Japan and Turkey when all age groups were considered. The above underscores the existence of SFI in the general populace of both Tropical, Sahel, Mediterranean, and Temperate regions, but particularly among adolescents in the tropics, the difference often lies in the specific type of SFI. Pityriasis versicolor was the most prevalent type in our survey and that by Ogunbiyi et al, ${ }^{4}$ it however only accounted for $4 \%$ in Hong Kong adolescents, 9 in whom tinea was the most prevalent SFI (60\%). Although both conditions are common in the tropics, PV is caused by malassezia species which are yeasts that form part of the skin microflora, while tinea is caused by dermatophyte fungus of soil, animals, or human origin, which invade keratinized tissues of humans and animals.

The low prevalence of PV in adolescents in Hong Kong compared to less developed countries with similar climatic conditions is somewhat puzzling. One of the major risk factors for PV is a warm and humid climate, but not indices related to poverty such as sub-optimal socioeconomic conditions, or poor personal and/or environmental hygiene. Thus, these cannot be stated as reasons for its preponderance in low income tropical countries but not in a similar but high income one. The explanation may lie in the multifactorial aetiology of PV infection, which requires an interplay of genetic and environmental factors as postulated by He et al. ${ }^{21}$ As regards environmental factors, we think that the heat index - which defines how the body perceives the ambient temperature and relative humidity of a given place - may have a role to play. The average heat index at the time of our survey in November 2008 was $46^{\circ} \mathrm{C}$ (calculated based on the aforementioned average temperature of $31.6^{\circ} \mathrm{C}$ and relative humidity of $87 \%$, using a heat index calculator freely available online). It may be a useful measure of one of the environmental factors that trigger pathogenicity in normal residents of the skin microbiome, e.g. malassezia species.

This however needs to be further studied, and may require that in addition to the period, researchers indicate the average temperature, and relative humidity at the time of their surveys, to allow for comparisons with similar surveys. The presence of PV, often called 'eczema' by the lay public and a good number of doctors in Nigeria has important implications in adolescents. The condition is rarely symptomatic, but the attendant discolouration accounts for the quest for treatment. In a study in Northern Nigeria, ${ }^{5}$ more than half the subjects thought the condition could be transmitted from person to person, and a little over one third felt it was caused by poor personal hygiene.

The major concerns of persons who reported having PV were: being considered dirty; progression of the disease to involve the whole body; possession of an ugly and unsightly skin; transmitting the disease to other people; and being avoided by others (so as not to pass it on to them). These can have adverse psychological effects on adolescents, for whom issues that alter their physical appearance, and by extension, attractiveness and acceptance can negatively impact their quality of life. Tinea was the second most common condition in this study, similar to that reported in Ibadan by Ogunbiyi et al. ${ }^{4}$

Although the prevalence was relatively low in Hong Kong, it still formed the most prevalent cutaneous infection. ${ }^{9}$ Tinea infection constitutes the most common infective dermatoses in most hospital based surveys in Nigeria14 and also accounts for the predominant condition in many Sub-Saharan African surveys involving a combination of children and young adolescents attending primary schools in Ghana, Gabon and Rwanda, Nigeria and Cote d'Ivoire. ${ }^{8,22,23}$ Tinea capitis was found to be the predominant type, and was more common in younger teenagers.

In contrast, pediculosis capitis, which was not found in our study, and is rarely found in surveys in Africa, was predominant among primary school surveys in Turkey, Saudi Arabia, and Egypt. ${ }^{24-26}$

An epidemiologic survey specific for Pediculosis capitis among primary school students in Ilorin, Nigeria revealed a prevalence of $3.7 \% .{ }^{27}$ Tinea capitis and pediculosis capitis are diseases of poverty and affect the hair/scalp. It is however curious that Pediculosis predominates in the relatively more affluent settings, while they are virtually absent in the Sub-Saharan Africa surveys. Tinea capitis appears to be more predominant in children of African descent as observed in a study in the United States of America. ${ }^{28}$ 
Our survey revealed a low prevalence of bacterial and viral infections. The former is more common in the paediatric age group, and in surveys with a high prevalence of scabies. ${ }^{10,29}$ The latter which was absent in two separate studies by the same author; one in children ${ }^{22}$ and the other in adolescents4 is more often seen in hospital based surveys, particularly in regions with Caucasoid and Asian ancestry. ${ }^{16,17,20}$ Parasitic infections were the least observed, with prevalence similar to that found in the Ibadan survey. ${ }^{4}$ A higher prevalence of $4.7 \%$ was however seen in younger subjects in the same locality. ${ }^{22}$

Insect bite reactions, specifically papular urticaria, are a relatively common condition in our environment where mosquitoes and other arthropods are abundant. The unhygienic environmental with stagnant water in dirty gutters, potholes in roads, and tall untended brushes surrounding homes and schools promote the growth and replication of disease causing/bearing insects. Most of the students had lesions on the exposed areas of the body, particularly on the legs, many of which were secondarily infected. A higher prevalence of $8.5 \%$ was reported in Ibadan. ${ }^{4}$

The attendant itching, secondary bacterial infection, and resultant discoloration with the 'spotty leg' appearance often causes distress to affected adolescents. In the article from which this present survey was extracted, papular urticaria was statistically more common among children attending affluent schools than in their public school counterparts. ${ }^{3}$ Gender variation in infectious dermatoses was observed in our survey. Males had significantly more PV and tinea than females. In a questionnaire-based survey by Yahya,${ }^{5}$ there were also more self-reports of PV by males.

A similar trend was observed in clinic based surveys, ${ }^{18,30}$ where significantly more males were diagnosed with PV; this is against the backdrop of females being more likely to visit health facilities for dermatologic consultations. ${ }^{31}$ However, a higher prevalence was reported in female undergraduates in Iran, ${ }^{32}$ among adolescents in Ibadan, 4 and in a skin clinic in India. ${ }^{33}$

Tinea infection as a whole was significantly more common among male students. This was mostly due to the relatively large number of young males with tinea capitis, which was the predominant form in the study. Similar findings were obtained in school surveys in Cote d'Ivoire and Ethiopia, ${ }^{24,34}$ although a clinic-based survey in a different region of the latter country revealed a female preponderance. ${ }^{35}$
Analysis of a significant number of records from a mycology laboratory in Sweden showed a higher frequency of males than females for all forms of tinea, except tinea faciei. ${ }^{36}$ In contrast a hospital based study in Egypt reported a female preponderance. ${ }^{15}$

A detailed review by Coulibaly et $\mathrm{al}^{37}$ has however overwhelmingly confirmed the higher prevalence of tinea infection in males. The reason for the gender variations is uncertain, extensive well-designed community-based surveys should be conducted to ascertain which gender is most at risk. This will open up the need for more research for the reason. Papular urticaria, candidiasis and furunculosis were more common in females, but the results were not statistically significant. A similar study showed a marked prevalence of papular urticaria among females 4 as has been observed in hospital-based surveys. ${ }^{38,39}$

Other authors have however found a higher male frequency in hospital records. ${ }^{18,40}$ Many of the female students were found to wear several layers of undergarments (mostly synthetic) underneath their school uniforms. Some individuals wore pant and brassiere; vests or tank tops; cycling shorts; and under skirts, all underneath their school uniforms. This degree of occlusive dressing, in addition to the high ambient temperature and humidity, are recognized factors for the development of cutaneous candidiasis and indeed furuncles.

\section{CONCLUSION}

The most common skin infection in teenage adolescents in our environment is pityriasis versicolor, a rarely symptomatic, non-contagious condition. It has the potential of affecting the self-esteem and quality of life of this vulnerable group of individuals, on account of the attendant skin discolouration, and its erroneous association with poor hygiene and contagiousness.

\section{REFERENCES}

1. Frisén A. Measuring health-related quality of life in adolescence. Acta Paediatr. 2007;96(7):963-968.

2. Golics CJ, Basra MKA, Finlay AY, Salek MS. Adolescents with Skin Disease Have Specific Quality of Life Issues. Dermatology. 2009 ;218(4):357-66.

3. Henshaw EB, Olasode OA, Ogedegbe EE, Etuk I. Dermatologic conditions in teenage adolescents in Nigeria. Adolesc Health Med Ther. 2014;5:79-87.

4. Ogunbiyi AO, Omigbodun Y, Owoaje E. Prevalence of skin disorders in school children in southwest Nigeria. Int J Adolesc Med Health;21(2):235-41.

5. Yahya H. Knowledge, perception, and practice of patients about pityriasis versicolor in Kaduna, North Central Nigeria. Int J Dermatol. 2017;56(11):116974. 


\section{Original Article}

6. Hekiert AM, Cohen MB, Montone KT, Palmer JN, Govindaraj S. Ecthyma gangrenosum mimicking acute invasive fungal sinusitis in an immunocompromised patient. Ear, Nose Throat J. 2010;89(6):2627.

7. Uludağ A, Oguz Kılıc S, Isık S, Ertekin YH, Tekin $\mathrm{M}$, Cevizci S, et al. Prevalence of skin disorders in primary and secondary school age children in Canakkale, Turkey: a community-based survey. $A d v$ Dermatology Allergol 2016;3(3):176-81.

8. Hogewoning A, Amoah A, Bavinck JNB, Boakye D, Yazdanbakhsh M, Adegnika A, et al. Skin diseases among schoolchildren in Ghana, Gabon, and Rwanda. Int J Dermatol. 2013;52(5):589-600.

9. ung WK, Lo KK. Prevalence of skin disease among school children and adolescents in a Student Health Service Center in Hong Kong. Pediatr Dermatol. 2018;17(6):440-6.

10. Dogra S, Kumar B. Epidemiology of skin diseases in school children: a study from northern India. Pediatr Dermatol.;20(6):470-3.

11. Chandigarh climate: Average Temperature, weather by month, Chandigarh weather averages - ClimateData.org. 2018 [cited 2018 Nov 4].

12. Morakinyo O, Ana G, Oloruntoba E. African journal of sustainable development. African $J$ Sustain Dev.;4(2):49-62.

13. Souissi A, Zeglaoui F, Zouari B, Kamoun MR. A study of skin diseases in Tunis. An analysis of 28,244 dermatological outpatient cases. Acta dermatovenerologica Alpina, Pannonica, Adriat. 2007;16(3):111-6.

14. Henshaw E, Ibekwe $\mathrm{P}$, Adeyemi A, Ameh S, Ogedegbe E, Archibong J, et al. Dermatologic Practice Review of Common Skin Diseases in Nigeria. Int J Heal Sci Res. 2018;2358(1).

15. 15. El-Khateeb EA, Imam AA, Sallam MA. Pattern of skin diseases in Cairo, Egypt. Int $J$ Dermatol.;50(7):844-53.

16. Furue M, Yamazaki S, Jimbow K, Tsuchida T, Amagai M, Tanaka T, et al. Prevalence of dermatological disorders in Japan: A nationwide, cross-sectional, seasonal, multicenter, hospital-based study. J Dermatol:;38(4):310-20.

17. Bilgili ME, Yildiz H, Sarici G. Prevalence of skin diseases in a dermatology outpatient clinic in Turkey. A cross-sectional, retrospective study. J Dermatol Case Rep. 2013;7(4):108-12.

18. El-Khateeb E. The spectrum of paediatric dermatoses in a university hospital in Cairo, Egypt. $J$ Eur Acad Dermatology Venereol. 2011;25(6):666-72.

19. Fekih Nadia E, Hajer A-S, Thabet-Dorbane Imen B, Faten Z, Mohamed Ridha kamoun, Becima F. Cutaneous infectious diseases in Tunisian adolescents. $J$ Public Heal Epidemiol. 2012;4(3):65-9.
20. Wenk C, Itin PH. Epidemiology of pediatric dermatology and allergology in the region of Aargau, Switzerland. Pediatr Dermatol.;20(6):482-7.

21. He S, Du W, Yang S, Zhou S, Li W, Wang J, et al. The genetic epidemiology of tinea versicolor in China. Mycoses. 2008;51(1):55-62

22. Ogunbiyi AO, Owoaje E, Ndahi A. Prevalence of Skin Disorders in School Children in Ibadan, Nigeria. Pediatr Dermatol. 2005;22(1):6-10.

23. Yotsu RR, Kouadio K, Vagamon B, N'guessan K, Akpa AJ, Yao A, et al. Skin disease prevalence study in schoolchildren in rural Côte d'Ivoire: Implications for integration of neglected skin diseases (skin NTDs). Vinetz JM, editor. PLoS Negl Trop Dis. 2018;12(5):e0006489.

24. Inanir I, Sahin MT, Gündüz K, Dinç G, Türel A, Oztürkcan S. Prevalence of skin conditions in primary school children in Turkey: differences based on socioeconomic factors. Pediatr Dermatol. 2002;19(4):307-11.

25. Al-Saeed WY, Al-Dawood KM, Bukhari IA, Bahnassy AA. Risk factors and co-morbidity of skin disorders among female schoolchildren in eastern Saudi Arabia. Invest Clin. 2007;48(2):199-212.

26. El-Khateeb EA, Lotfi RA, Abdel-Aziz KM, ElShiekh SE. Prevalences of skin diseases among primary schoolchildren in Damietta, Egypt. Int J Dermatol. 2014;53(5):609-16.

27. Ebomoyi EW. Pediculosis capitis among urban school children in Ilorin, Nigeria. $J$ Natl Med Assoc. 1994;86(11):861-4.

28. Coloe J, Diab M, Moennich J, Diab D, Pawaskar M, Balkrishnan R, et al. Tinea capitis among children in the Columbus area, Ohio, USA. Mycoses. 2010;53(2):158-62.

29. Vora R, Bodiwala N, Patel S, Krishna S. Prevalence of Various Dermatoses in School Children of Anand District. Natl J Community Med. 2012;3(1):100-3.

30. Snekavalli R, Madhu R, Ramesh A, Janaki C, Dhanalakshmi U. Clinico epidemiological and mycological study of pityriasis versicolor. Int J Res Med Sci. 2018;6(6).

31. Henshaw EB, Olasode OA. Skin diseases in Nigeria: The Calabar experience. Int J Dermatol. 2015;54(3).

32. Ebrahimzad A. A Survey on Pityriasis Versicolor in the University Students in Southeast of Iran. Asian J Dermatology. 2009;1(1):1-5.

33. Meera G, Thilak S, Jefferson J. A study of 200 cases of pityriasis versicolor: the distribution of age, gender, blood group, lesion morphology, hemoglobin levels, cholesterol levels and diabetic status. Int $J$ Res Dermatology. 2017;3(1):20-3.

34. Alemayehu A, Minwuyelet, Gebremedhin Andualem G. Prevalence and Etiologic Agents of 
Dermatophytosis among Primary School Children in Harari Regional State, Ethiopia. J Mycol. 2016;2016:5.

35. Teklebirhan G, Bitew A. Prevalence of Dermatophytic Infection and the Spectrum of Dermatophytes in Patients Attending a Tertiary Hospital in Addis Ababa, Ethiopia. Int J Microbiol. 2015;

36. Drakensjö IT, Chryssanthou E. Epidemiology of dermatophyte infections in Stockholm, Sweden: a retrospective study from 2005-2009. Med Mycol. 2010;49(5):1-5.

37. Coulibaly O, L'Ollivier C, Piarroux R, Ranque S. Epidemiology of human dermatophytoses in Africa. Med Mycol. 2018;56(2):145-61.
38. Altraide DD, Akpa MR, George IO. The pattern of skin disorders in a Nigerian tertiary hospital. J Public Heal Epidemiol. 2011;3(4):177-81.

39. Balai M, Khare AK, Gupta LK, Mittal A, Kuldeep CM. Pattern of pediatric dermatoses in a tertiary care centre of South West Rajasthan. Indian J Dermatol. 2012;57(4):275-8.

40. Del Pozzo-Magaña BR, Lazo-Langner A, GutiérrezCastrellón P, Ruiz-Maldonado R. Common Dermatoses in Children Referred to a Specialized Pediatric Dermatology Service in Mexico: A Comparative Study between Two Decades. ISRN Dermatol.2012:1-5. 